\title{
AN IRRIGATION WATER DISTRIBUTION MODEL FOR AREA OF MIXED CULTIVATION
}

\author{
Ching-Tien Chen, Chun-E Kan, and Gwo-Fong Lin*
}

\begin{abstract}
A water distribution model is presented which is capable of satisfying water demand in an area with large-scale mixed cultivation during the water-shortage periods. The proposed model is based on a new parameter called modified $K$-factor in which farm areas, canal and ditch lengths, and crop types are considered. Actual applications show that the proposed model has advantages over the model based on the original $K$-factor. The proposed model can deliver appropriate amounts of irrigation water to specific blocks at the right time, fairly and rationally. The model can be applied to either a main or to a lateral canal system. It is found that the water distribution of the main canal system is to be preferred for severe water shortages.
\end{abstract}

Key Words: water distribution; field irrigation requirements; mixed cultivation.

\section{INTRODUCTION}

The common practice of irrigation water distribution has been constructed based on single crops over large areas. Typical examples are paddy rice agriculture in Japan and Taiwan (Pereira et al., 1993; Masakazu, 1999; Chang et al., 2001) and upland crop agriculture in American and European countries (Droogers et al., 1999). Since there is only one crop in the irrigation service area, the water distribution practice can achieve accuracy to a certain extent. However, as crop diversity has become a trend in maintaining the competitiveness of agricultural productivity (Masayoshi, 1999), the mixing of paddy rice and upland crops in an irrigation service area will be more common in Taiwan. Since various crops have to be considered and their growth periods are different, the irrigation practice will become more difficult. The water demands of upland crops are often ignored or estimated by using only a representative crop in the whole irrigation service area. Although using such simplified

*Corresponding author. (Tel: 886-2-23629023; Fax: 886-223631558; Email: gflin@ @ntu.edu.tw)

C. T. Chen and C. E. Kan are with the Department of Bioenvironmental Systems Engineering, National Taiwan University, Taipei, Taiwan 106, R.O.C., and C. T. Chen is currently at the Department of Civil and Water Resources Engineering, National Chia-Yi University, Chia-Yi, Taiwan 621, R.O.C.

G. F. Lin is with the Department of Civil Engineering, National Taiwan University, Taipei, Taiwan 106, R.O.C. methods may reduce the cost of irrigation management, the growth of crops is affected. Hence, it is justified to establish an irrigation water distribution model that accounts for the actual situation of mixed cultivation.

Regarding irrigation water distribution during water shortage periods, Pasandaran et al. (1989) proposed the $K$-factor method for solving the water distri-bution problem. However, this method is applicable only for minor shortage conditions. In addition, the calculation of system conveyance loss is inadequate. The $K$-factor method considers the total conveyance loss for the whole irrigation service area. However, in actual practice of rotational irrigation, only parts of the whole irrigation service areas are irrigated. For systematic water distribution in large paddy areas, Kan and Hsu (1984) proposed an adjusted irrigation plan by lengthening the rotational irrigation periods. Nevertheless, the distribution efficiency and amounts of water distributed under various shortage conditions were not discussed. Lin (1992) attempted to estimate the water distribution efficiency based on the weighting of canal lengths and rotational farm units. Kan et al. (1997a) and Chen et al. (1997) respectively modified the calculation of system conveyance loss in the $K$ factor method according to farm areas and canal lengths. However, they did not consider the water distribution in laterals and farm units in a mixed-cultivation situation. Therefore, there is a need to establish a water distribution model according to the farm areas, canal and ditch lengths, crop types and canal systems in order to satisfy the water requirements for various crops. 
This paper is organized as follows. Factors affecting water distribution are investigated in Section II. In Section III, a water distribution model is established which is capable of satisfying water demand in large-scale mixed cultivation irrigation areas during water shortage periods. Application of the proposed model and the corresponding discussions of the simulated results are presented in Section IV. Finally, conclusions are given in Section V.

\section{FACTORS AFFECTING WATER DISTRIBUTION}

The irrigation water distribution requires overall consideration of crop types, growing stages, crop water requirements, percolation, conveyance loss, and effective rainfall, etc. These factors vary with time and locations. Consequently, how to convey an adequate amount of water to specific blocks at the right time in large areas requires sophisticated professional skill. The corresponding factors are discussed as follows.

\section{Crop Water Requirement}

The crop water requirement (CWR) can be determined by direct measurement or through indirect estimation. Although direct measurement can yield an actual water requirement, it requires more money and labor due to morphological constraints. Instead, the indirect estimation is generally used. The estimation equation is expressed as

$$
q_{j k}^{\mathrm{CWR}}=\mathrm{CC}_{j k} \times \mathrm{ET}_{k}^{\mathrm{refer}}
$$

where $q_{j k}^{\text {CWR }}$ is the crop water requirement for the $j$ th crop during the $k$ th irrigation period per hectare of irrigation area, $\mathrm{CC}_{j k}$ is the dimensionless crop coefficient for the $j$ th crop during the $k$ th irrigation period, and $\mathrm{ET}_{k}^{\text {refer }}$ is the reference evapotranspiration of standard crop canopy during the $k$ th irrigation period per hectare of irrigation area. The $\mathrm{ET}_{k}^{\text {refer }}$ is often estimated using the Penmen-Monteith method (Monteith, 1994; Kan et al., 1996). As to the crop coefficients, one can use the values recommended by the Food and Agriculture Organization (Doorenbos and Pruitt, 1977). Then, according to the growing seasons of all crops (paddy rice and upland crops), one can determine the total crop water requirement for any period.

\section{Percolation in Paddy Fields}

The percolation process in paddy fields is very complicated and varies with soil texture, ponding depth, water temperature, groundwater level, extension of root system, etc. In Taiwan the percolation in paddy fields is estimated using an empirical formula from the Taiwan Water Conservancy Bureau (Kan, 1978).

\section{Effective Rainfall}

Effective rainfall is the amount of rainfall that can be utilized by crops. From the viewpoint of irrigation managers, the amount of rainfall helpful to reduce the irrigation water supply is considered as effective rainfall. Because rainfall itself is uncontrollable, there are yet no accepted criteria for the estimation of effective rainfall. For areas with mixed cultivation of paddy rice and upland crops, one used to consider only the effective rainfall for paddy rice. However, for the ideal management of irrigation water, one needs to estimate the effective rainfalls for the paddy rice and upland crops separately.

Regarding the estimation of the effective rainfall for paddy rice, each irrigation association in Taiwan generally adopts its own experimental result that does not exceed $60 \%$ of mean precipitation or $50 \%$ of field water requirement, whichever is least. As to the estimation of the effective rainfall for upland crops, daily precipitation within $50 \mathrm{~mm}$ can be regarded as effective rainfall according to the experimental results of the Taiwan Water Conservancy Bureau (Kan, 1978).

\section{Conveyance Loss in Canals and Ditches}

Conveyance loss is the water lost during the conveyance process from source to fields, including evaporation, seepage, operation loss, etc. The conveyance path consists of a main canal (from the main intake to a lateral intake), a lateral canal (from the lateral intake to a farm intake), and ditches (from the farm intake to fields). In the past practice of irrigation, the conveyance losses in canals and ditches were generally considered as constant, which is inadequate. In this paper, methods for estimating the conveyance losses in canals and ditches are proposed in Sections III.1.(i) and III.1.(ii).

\section{Water Requirement for Land Preparation}

During land preparation, the field is ploughed and a considerable amount of water is applied so that soil is saturated and is ready for the transplantation of paddy. Theoretically, the water requirement for land preparation is composed of irrigation for paddy rice and the water needed to saturate the soil. The amount of water required for land preparation generally ranges from 120 to $200 \mathrm{~mm}$ (Cheng, 1980).

\section{WATER DISTRIBUTION MODEL}

\section{Development of Model}

The model to be developed can convey the 
appropriate amount of water to specific blocks at the right time under various circumstances, while agricultural production is not affected. For irrigation water distribution in an area of mixed cultivation during water shortage periods, Pasandaran et al. (1989) proposed the $K$-factor

$$
K=\frac{\text { Available water }}{\text { Gross water demand }}
$$

For the $k$ th irrigation period, the $K$-factor is expressed as $K_{k}$ herein. The $K$-factor is applicable during minor water shortage periods in which uniform reduction of water distributed is used. For rotational irrigation, the calculation of system conveyance loss is inadequate. The $K$-factor considers the total conveyance loss for the whole irrigation service area, although only a part of the area is actually irrigated. The $K$-factor cannot consider only the actual irrigation area and the conveyance path from the water source to the farm units to be irrigated. Hence, the water is wasted due to inadequate calculation of conveyance loss. In this paper, a procedure called modified $K$-factor is proposed in which farm areas, canal and ditch lengths, and crop types are considered. The modified $K$-factor is written as

$$
\widetilde{K}_{k}=\frac{Q_{k}^{\text {actual }}-Q_{k}^{\text {loss }}}{Q_{k}^{\text {project }}-Q_{k}^{\text {loss }}}
$$

where $\widetilde{K}_{k}$ is the $K$-factor for the $k$ th irrigation period, $Q_{k}^{\text {actual }}$ is the actual amount of water delivered to the system during the $k$ th irrigation period, $Q_{k}^{\text {project }}$ is the projected water demand of the system during the $k$ th irrigation period, and $Q_{k}^{\text {loss }}$ is the conveyance loss of the system during the $k$ th irrigation period. The system herein refers to a main or lateral canal water distribution system.

\section{(i) Conveyance Loss Coefficient for Ditches in a Farm Unit}

When water is delivered from the intake of the rotational irrigation block (referred to as the farm intake herein) to fields through ditches, some water is lost in ditches. Hence, to obtain the projected water demand at the farm intake, a correction coefficient should be applied to the amount of water as calculated from the field irrigation requirement (see Eq. (8)). The correction coefficient is referred to as the conveyance loss coefficient (CLC) herein. In the past practice of irrigation, the CLC for any farm unit was taken as

$$
\mathrm{CLC}^{\mathrm{farm}}=1+S
$$

where $S$ is the water loss in decimals and an empirical value of 0.2 or 0.25 is often used. In this paper the conveyance loss in ditches of a farm is regarded as a variable. Hence, the CLC for the $i$ th farm is expressed as

$$
\mathrm{CLC}_{i}^{\mathrm{farm}}=1+S_{i}
$$

where

$$
S_{i}=S_{\text {exp }}\left(A_{i} / A_{\text {exp }}\right)\left(\sum_{i=1}^{n} S_{i} / n\right)\left(\sum_{i=1}^{n} A_{i} S_{i} / \sum_{i=1}^{n} A_{i}\right)^{-1}
$$

where $S_{\exp }$ is the experimental water loss of a farm with an area of $A_{\text {exp }}, A_{i}$ is the area of the $i$ th farm, and $n$ is the total number of farm units. The $\left(A_{i} / A_{\text {exp }}\right)$ is introduced to consider the effect of the farm size on the water loss, which yields a larger value of water loss for a larger area of farm. The $\sum_{i=1}^{n} S_{i} / n$ is the average water loss and $\sum_{i=1}^{n} A_{i} S_{i} / \sum_{i=1}^{n} A_{i}$ is the areaweighted average water loss for all farms. They are introduced to yield a more rational estimate of the water loss in ditches of the ith farm (Kan et al., 1997b; Lin, 1992 ).

\section{(ii) Conveyance Loss Coefficient for Main and Lateral Canals}

The same considerations apply to the calculation of the projected water demand at the lateral intake and main intake as the water losses in lateral and main canals are considered (see Eqs. (10) and (11)). In the past practice of irrigation, the conveyance loss in canals was regarded as a constant no matter for how long the water was delivered. That is $\mathrm{CLC}^{\mathrm{canal}}=1$ $+C$ where $C$ is the water loss in canals in decimals. In fact, the shorter the distance from the intake to the farm unit is, the smaller the conveyance loss is. Hence, the conveyance loss from the canal intake to a farm intake is regarded as a variable in this paper. Furthermore, the CLC is expressed as

$$
\mathrm{CLC}_{i}^{\mathrm{canal}}=1+C_{\mathrm{exp}} L_{i}\left(\sum_{i=1}^{n} L_{i} / n\right)^{-1}
$$

where $C_{\text {exp }}$ is the experimental water loss in decimals, $L_{i}$ is the canal length from the canal intake to the $i$ th farm unit, and $\sum_{i=1}^{n} L_{i} / n$ is the average canal length. The $L_{i}\left(\sum_{i=1}^{n} L_{i} / n\right)^{-1}$ is introduced to give a rational estimate of the water loss in canals (Kan et al., 1997b; Lin, 1992), which can reflect the influence of the canal length on the water loss.

\section{(iii) Projected Water Demand at the Farm Intake}

For an area of mixed cultivation of paddy rice and upland crops, previous irrigation water distribution practices usually considered only the water 
demand for the paddy rice. As to the upland crops, their water demands were often neglected or estimated from a representative crop. In this paper, the actual situation of mixed cultivation is considered.

The projected water demand at the farm intake for the $j$ th crop in the $i$ th farm unit during the $k$ th irrigation period is

$$
Q_{i j k}^{\text {project, farm }}=q_{j k}^{\mathrm{FIR}} \times A_{i j} \times \mathrm{CLC}_{i}^{\mathrm{farm}}
$$

where $q_{j k}^{\mathrm{FIR}}$ is the field irrigation requirement (FIR) for the $j$ th crop during the $k$ th irrigation period per hectare of irrigation area, and $A_{i j}$ is the area for the $j$ th crop in the $i$ th farm unit. The $q_{j k}^{\mathrm{FIR}}$ can be computed from

$$
q_{j k}^{\mathrm{FIR}}=q_{j k}^{\mathrm{CWR}}+q_{j}^{\mathrm{P}}-q_{j k}^{\mathrm{ER}}
$$

where $q_{j k}^{\mathrm{CWR}}$ is the crop water requirement (CWR) for the $j$ th crop during the $k$ th irrigation period per hectare of irrigation area as defined in Eq. (1), and $q_{j k}^{\mathrm{ER}}$ is the effective rainfall (ER) for the $j$ th crop during the $k$ th irrigation period per hectare of irrigation area, and $q_{j}^{\mathrm{p}}$ is the percolation in paddy fields for the $j$ th crop per hectare of irrigation area. It should be noted that $q_{j}^{\mathrm{p}}$ is zero for upland crops.

\section{(iv) Projected Water Demand at Lateral and Main Canal Intakes}

Once the projected water demand at the farm intake for the $j$ th crop in the $i$ th farm unit during the $k$ th irrigation period, $Q_{i j k}^{\text {project, farm }}$, is determined, the corresponding projected water demand at a lateral canal intake can then be calculated from

$$
Q_{i j k}^{\text {project, lateral }}=Q_{i j k}^{\text {project, farm }} \times \mathrm{CLC}_{i}^{\text {lateral }}
$$

where $\mathrm{CLC}_{i}^{\text {lateral }}$ is the conveyance loss coefficient for the lateral canal which delivers water to the $i$ th farm intake.

From Eq. (10), one can obtain the projected water demand for a certain lateral canal intake. Then taking into account the conveyance loss between this lateral canal intake and the main canal intake, one can obtain the corresponding projected water demand at the main canal intake as

$$
Q_{i j k}^{\text {project, main }}=Q_{i j k}^{\text {project, lateral }} \times \mathrm{CLC}_{i}^{\text {main }}
$$

where $\mathrm{CLC}_{i}^{\text {main }}$ is the conveyance loss coefficient for main canal between the lateral and main canal intakes.

For areas with mixed cultivation of crops, for example paddy rice and upland crops, the projected water demand at a lateral canal intake during the $k$ th irrigation period can be calculated from

$$
Q_{k}^{\text {project, lateral }}=\sum_{i=1}^{n} \sum_{j=1}^{r} Q_{i j k}^{\text {project, lateral }}
$$

where $n$ is the number of farm units, and $r$ is the number of crop types. In a like manner, one can obtain the projected water demand at the main canal intake during the $k$ th irrigation period

$$
Q_{k}^{\text {project, main }}=\sum_{i=1}^{n} \sum_{j=1}^{r} Q_{i j k}^{\text {project, main }}
$$

Subsequently, the water loss of a lateral canal during the $k$ th irrigation period is

$$
Q_{k}^{\text {loss, lateral }}=Q_{k}^{\text {project, lateral }}-Q_{k}^{\text {project, farm }}
$$

Likewise, the water loss of a main canal during the $k$ th irrigation period is written as

$$
Q_{k}^{\text {loss, main }}=Q_{k}^{\text {project, main }}-Q_{k}^{\text {project, lateral }}
$$

\section{(v) Modified Farm Water Demand}

In this paper, the modified $K$-factor of Eq. (3) is used to distribute the water to meet the farm water demand during the $k$ th irrigation period, $Q_{k}^{\text {project }}$, during a water shortage (i.e., under a given actual water supply $Q_{k}^{\text {actual }}$ ). Eq. (3) can be applied to a main or lateral canal. For example, for the water distribution of a lateral canal, the $Q_{k}^{\text {project }}, Q_{k}^{\text {loss }}$, and $Q_{k}^{\text {actual }}$ in Eq. (3) refer to $Q_{k}^{\text {project, lateral, }}, Q_{k}^{\text {loss, lateral }}$, and $Q_{k}^{\text {actual, lateral }}$, respectively. The $Q_{k}^{\text {project, lateral }}$ and $Q_{k}^{\text {loss, lateral }}$ are obtained from Eqs. (12) and (14). Once the modified $K$-factor, $\widetilde{K}_{k}$, is determined, one can find the modified projected farm water demand for the $i$ th farm unit during the $k$ th irrigation period as

$$
\widetilde{Q}_{i k}^{\text {project, farm }}=\widetilde{K}_{k} \times Q_{i k}^{\text {project, farm }}
$$

\section{Water Distribution Schemes during Water Shortages}

\section{(i) Uniform Water Reduction}

When there is no water shortage during the $k$ th irrigation period $\left(K_{k} \geq 1.0\right)$, one can implement the normal irrigation plan. If the water supply is slightly deficient $\left(0.75<K_{k}<1.0\right)$, one can use a plan called uniform reduction method (Pasandaran et al., 1989; Kan et al., 1997a). This method reduces, by the same amount, the water allocated to each farm unit, while the whole irrigation service area is still irrigated simultaneously.

\section{(ii) Rotation among Irrigation Groups}

When the water supply is further deficient during the $k$ th irrigation period $\left(K_{k}<0.75\right)$, the water source is not capable of providing enough water head 
(i.e., the water depths in canals from lateral intakes to farm intakes are not deep enough) to deliver water to the whole irrigation service area. Hence, the rotation among irrigation groups method should be implemented. This method divides the whole irrigation service area into several groups. Each group contains several farm units. It should be noted that the farm unit is the basic unit in the rotation among irrigation groups method. When this method is implemented, the water is only delivered to certain groups at any one time (Chen et al., 1998).

The rotation intervals and the number of rotation groups depend on the total readily available moisture of soils and the drought tolerance of crops in the irrigation service area. Once the rotation intervals and the number of rotation groups are confirmed, the mode of rotation is dependent on the water available for irrigation. The following rotation modes are adopted. When $K_{k}=0.75$, three out of four groups are irrigated at a time; when $0.5<K_{k}<0.75$, two out of three; when $K_{k}=0.5$, one out of two; when $0.25 \leq K_{k}$ $<0.5$, one out of three. When the water is in extreme deficiency $\left(K_{k}<0.25\right)$, one can deliver water only to part of the irrigation service area (Chen et al., 1998).

\section{APPLICATION AND DISCUSSIONS}

Actual application of the proposed model is presented to demonstrate the applicability of the model. An irrigation area with a considerable scale of mixedcultivation in southern Taiwan is selected herein for application of the model.

\section{Study Area}

The study area, with a size of 65,195 ha, belongs to the Chia-Nan Irrigation Association. There are 2 main canals (South Main 10,073 m long, and North Main 47, $251 \mathrm{~m}$ long), 44 laterals, and 2,022 farm units in the study area. A schematic diagram of mains, laterals and farm units for the study area is shown in Fig. 1. It should be noted that the length of canal in Fig. 1 refers to the canal length between the main and lateral intakes or between the lateral and farm intakes. The study area lies in a subtropical climate. According to the meteorological records (from 1951 to 1999), the lowest, mean, and highest annual temperatures are 13, 24, and 33 degrees Celsius, and the mean daily evaporation is $3.5 \mathrm{~mm} /$ day. The wet season is from May to September, and the dry season is from October to April. The soil is mainly composed of loam ( $17.11 \%$ clay, $47.95 \%$ silt, and $34.94 \%$ sand) and silt loam (13.05\% clay, $50.26 \%$ silt, and $36.69 \%$ sand). Crops are paddy rice, sugar cane, corn, peanuts, and vegetables. The first-season paddy rice begins in late January and ends in mid-May, while the second-season paddy rice begins in early June and ends in early November. The sugar cane begins in early January and ends in early December. The other upland crops only grow in spring and summer.

\section{Assessment of Model Performance}

For easy comparison and clear demonstration of the model performance using the original and the modified $K$-factor methods, a criterion named the coefficient of efficiency is used herein. The coefficient of efficiency (CE) is defined as

$$
\mathrm{CE}_{k}=1-\frac{\sum_{i=1}^{n}\left[Q_{i k}-Q_{i k}^{\text {actual }}\right]^{2}}{\sum_{i=1}^{n}\left[Q_{i k}-\bar{Q}_{k}\right]^{2}}
$$

where $\overline{Q_{k}}=\left(\sum_{i=1}^{n} Q_{i k}\right) / n$ is the average farm water demand during the $k$ th irrigation period, $Q_{i k}$ is the projected farm water demand for the $k$ th irrigation period in the $i$ th farm unit, $Q_{i k}^{\text {actual }}$ is the actual amount of water delivered to the $i$ th farm unit during the $k$ th irrigation period, and $n$ is the number of farm units. The suitability is higher when CE is closer to 1 as the amount of water actually distributed matches the projected water demand better.

\section{Field Irrigation Requirement}

Using Eq. (9), one can calculate the field irrigation requirement for the $j$ th crop during the $k$ th irrigation period per hectare of irrigation area. Fig. 2 shows the field irrigation requirements per hectare of irrigation area for various crops, namely, paddy rice, vegetable, sugar cane, peanuts and corn. As shown in Fig. 2, the field irrigation requirement of paddy rice is higher than that of the upland crops, and its peaks occur during land-preparation periods. In addition, the field irrigation requirements of all crops in the study area show a trend of multiple peaks during their growing stages. This phenomenon results from the influence of climate and precipitation. Such a unique trend of field irrigation requirement in Taiwan prompts the application of water distribution.

Fig. 3 gives the estimates of total field irrigation requirements of the study area for different treatments of upland crops. As shown in Fig. 3, the case that considers all the upland crops in the estimation yields the highest field irrigation requirement. The case that ignores upland crops and the case that considers only the sugar cane as the single upland crop underestimate the field irrigation requirement. Hence, to assure the normal growth of paddy rice and all upland crops, one should use the field irrigation requirement, which accounts for the actual situation of mixed cultivation for mobile water distribution. 


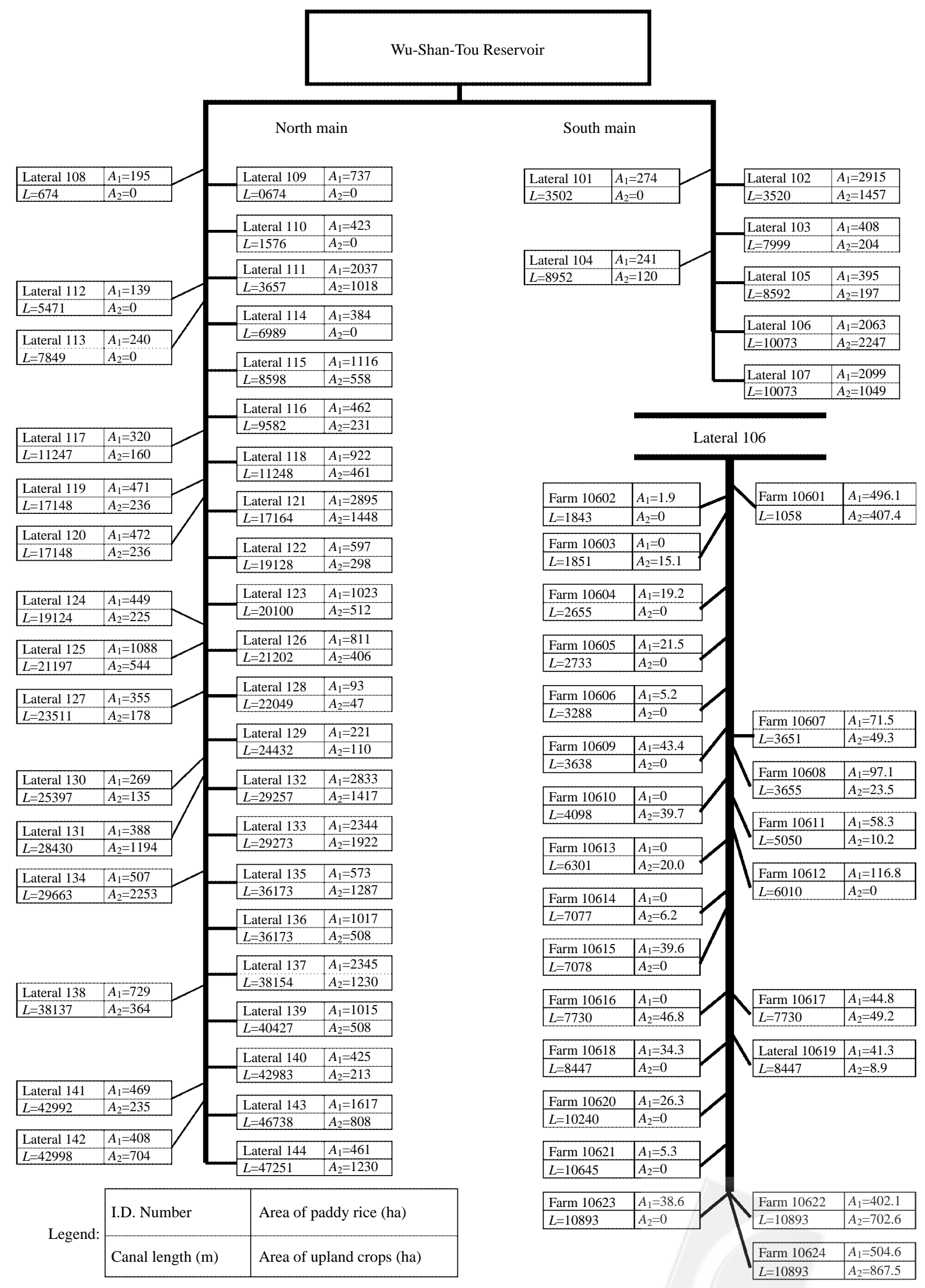

Fig. 1 Schematic diagram of mains, laterals and farms in the Chia-Nan irrigation district 


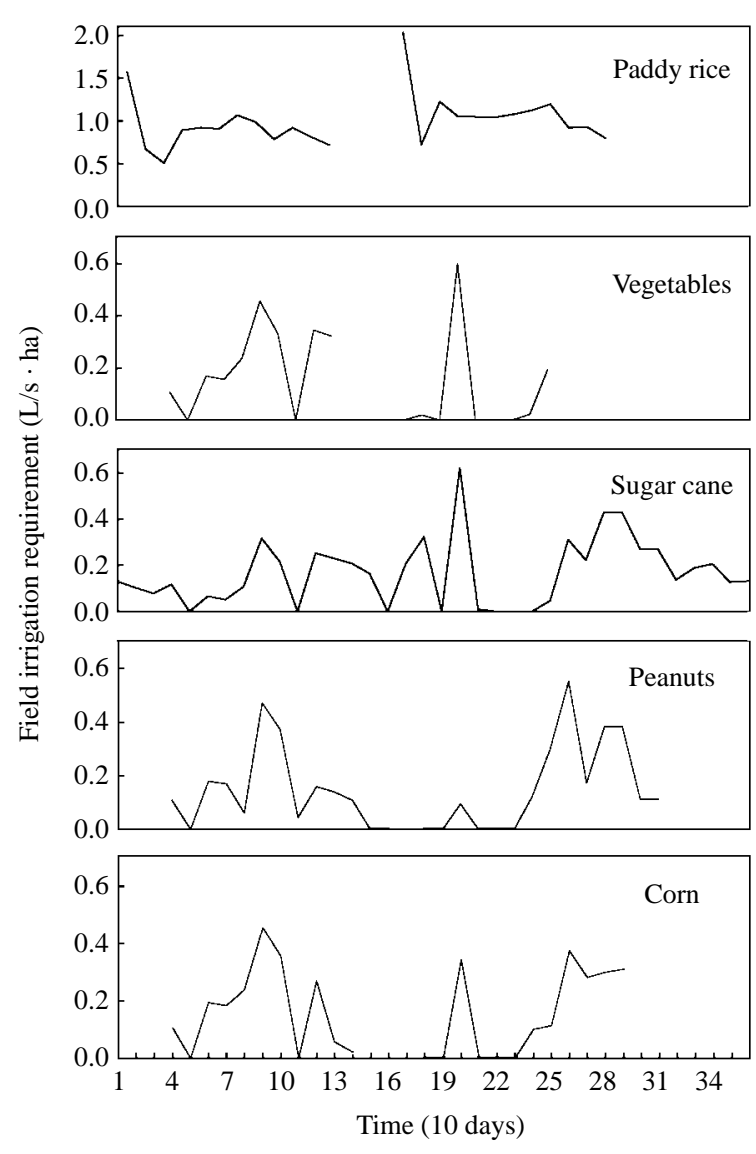

Fig. 2 Field irrigation requirements per hectare of irrigation area for various crops

\section{Conveyance Loss and Projected Water Demand}

The conveyance loss coefficients for a farm unit and a canal can be estimated using Eqs. (5) and (7), respectively. The conveyance loss coefficients related to Lateral 106 are given in Table 1. As shown in Table 1 , the mean conveyance loss coefficient for farm units is 1.126 , and that for canals is 1.150 . Once the conveyance loss coefficient of a farm unit is obtained, the corresponding projected farm water demand can be computed using Eq. (8). Furthermore, the projected water demand at the lateral intake can be obtained from Eq. (10). For the system of Lateral 106, these two types of water demands during the period of August 1 to 10 are given in Table 1. As shown in Table 1, the projected farm water demand is $3,658 \mathrm{~L} / \mathrm{sec}$, and the projected water demand at the later intake is $4,501 \mathrm{~L} / \mathrm{sec}$. The difference between these two values, $843 \mathrm{~L} / \mathrm{sec}$, is the water loss of Later 106 as defined in Eq. (14).

In a like manner, one can apply the methodology to the whole irrigation district. The mean conveyance loss coefficients are $1.105,1.097$ and 1.10 for farm units, laterals, and mains, respectively (see Table 2). The corresponding projected water demands

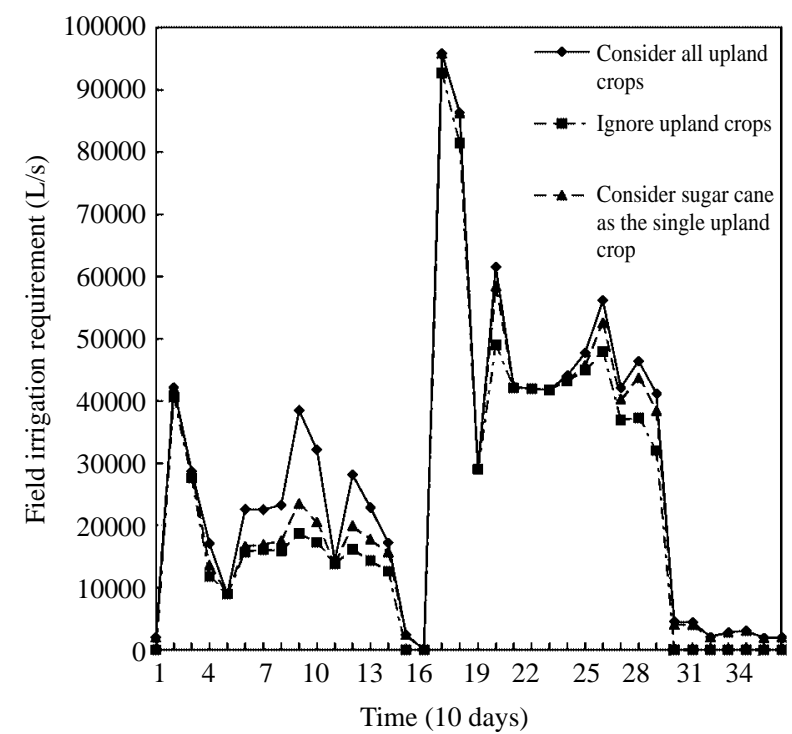

Fig. 3 Estimates of field irrigation requirements for different treatments of upland crops

at the intakes of farms, laterals and mains are 50,824, 58,303 , and 64,199 L/sec, respectively (see Table 2). Furthermore, according to Eqs. (14) and (15), the water loss of lateral canals is $7,499 \mathrm{~L} / \mathrm{sec}$ and that for main canals is $5,896 \mathrm{~L} / \mathrm{sec}$.

\section{Water Distribution for Mixed Cultivation}

The aforementioned water distribution schemes during water shortages (see Section III.2) are applied to the study area (see Fig. 1). The performances of schemes based on the original and modified $K$-factor methods are compared. As a water shortage may occur in any growing stage, the results during the period of August 1 to 10 are presented as an example.

\section{(i) Water Distribution in Main Canals}

Five water deficits, namely $801,1,401,1,901$, 20,501 , and $29,501 \mathrm{~L} / \mathrm{s}$ (referred to as $S_{1}, S_{2}, S_{3}, S_{4}$ and $S_{5}$ in Table 3 ), are considered. Table 3 presents the amounts of water delivered to each lateral intake under various water shortages using the original and the modified $K$-factor methods. According to the methodology presented in Section III.2, the uniform reduction method is adopted for cases with water shortages of $S_{1}\left(K_{k}=0.99\right), S_{2}\left(K_{k}=0.98\right)$ and $S_{3}\left(K_{k}=\right.$ 0.97 ), while the rotation among irrigation groups method should be implemented for cases with water shortages of $S_{4}\left(K_{k}=0.65\right)$ and $S_{5}\left(K_{k}=0.5\right)$. For Case $S_{4}$, two out of three groups are irrigated at a time, and the three groups are $G_{1}$ (Laterals 101 to 115 ), $G_{2}$ (Laterals 116 to 132 ), and $G_{3}$ (Laterals 133 to 144). As to Case $S_{5}$, one out of two groups is irrigated at a 
Table 1 Water demand at farm and lateral intakes for each farm unit of Lateral 106

\begin{tabular}{|c|c|c|c|c|c|c|c|c|c|}
\hline \multirow[t]{2}{*}{$\begin{array}{l}\text { Farm } \\
\text { number }\end{array}$} & \multicolumn{5}{|c|}{$\begin{array}{l}\text { Area } \\
\text { (ha) }\end{array}$} & \multicolumn{2}{|c|}{$\begin{array}{c}\text { Conveyance loss } \\
\text { coefficient }\end{array}$} & \multicolumn{2}{|c|}{$\begin{array}{l}\text { Water demand } \\
(\mathrm{L} / \mathrm{s})\end{array}$} \\
\hline & Rice & $\begin{array}{l}\text { Sugar } \\
\text { cane }\end{array}$ & Corn & Peanuts & Vegetables & Farm & Lateral & $\begin{array}{l}\text { Farm } \\
\text { intake }\end{array}$ & $\begin{array}{c}\text { Lateral } \\
\text { intake }\end{array}$ \\
\hline 10601 & 496.1 & 180.0 & 100.0 & 73.0 & 54.4 & 1.637 & 1.023 & 908 & 929 \\
\hline 10602 & 1.9 & 0.0 & 0.0 & 0.0 & 0.0 & 1.001 & 1.041 & 2 & 2 \\
\hline 10603 & 0.0 & 0.0 & 0.0 & 0.0 & 15.1 & 1.011 & 1.041 & 0 & 0 \\
\hline 10604 & 19.2 & 0.0 & 0.0 & 0.0 & 0.0 & 1.013 & 1.059 & 21 & 22 \\
\hline 10605 & 21.5 & 0.0 & 0.0 & 0.0 & 0.0 & 1.015 & 1.061 & 23 & 25 \\
\hline 10606 & 5.2 & 0.0 & 0.0 & 0.0 & 0.0 & 1.004 & 1.073 & 6 & 6 \\
\hline 10607 & 71.5 & 20.0 & 15.0 & 10.0 & 4.3 & 1.085 & 1.081 & 87 & 94 \\
\hline 10608 & 97.1 & 10.0 & 5.0 & 4.0 & 4.5 & 1.085 & 1.081 & 115 & 124 \\
\hline 10609 & 43.4 & 0.0 & 0.0 & 0.0 & 0.0 & 1.031 & 1.091 & 48 & 53 \\
\hline 10610 & 0.0 & 20.0 & 8.0 & 7.0 & 4.7 & 1.028 & 1.112 & 2 & 2 \\
\hline 10611 & 53.3 & 8.0 & 2.2 & 0.0 & 0.0 & 1.045 & 1.133 & 60 & 68 \\
\hline 10612 & 116.8 & 0.0 & 0.0 & 0.0 & 0.0 & 1.082 & 1.140 & 136 & 155 \\
\hline 10613 & 0.0 & 10.0 & 5.0 & 0.0 & 5.3 & 1.014 & 1.157 & 1 & 1 \\
\hline 10614 & 0.0 & 0.0 & 0.0 & 0.0 & 6.2 & 1.004 & 1.157 & 0 & 0 \\
\hline 10615 & 39.6 & 0.0 & 0.0 & 0.0 & 0.0 & 1.028 & 1.171 & 44 & 51 \\
\hline 10616 & 0.0 & 20.0 & 10.0 & 13.0 & 3.8 & 1.033 & 1.171 & 3 & 3 \\
\hline 10617 & 44.8 & 30.0 & 5.0 & 10.0 & 4.2 & 1.066 & 1.187 & 53 & 63 \\
\hline 10618 & 34.3 & 0.0 & 0.0 & 0.0 & 0.0 & 1.024 & 1.187 & 38 & 45 \\
\hline 10619 & 41.3 & 0.0 & 0.0 & 8.9 & 0.0 & 1.035 & 1.227 & 47 & 58 \\
\hline 10620 & 26.3 & 0.0 & 0.0 & 0.0 & 0.0 & 1.019 & 1.236 & 29 & 36 \\
\hline 10621 & 5.3 & 0.0 & 0.0 & 0.0 & 0.0 & 1.004 & 1.242 & 6 & 7 \\
\hline 10622 & 402.1 & 362.0 & 138.0 & 134.0 & 68.6 & 1.763 & 1.242 & 827 & 1027 \\
\hline 10623 & 38.6 & 0.0 & 0.0 & 0.0 & 0.0 & 1.027 & 1.242 & 43 & 53 \\
\hline 10624 & 504.6 & 390.0 & 216.0 & 178.0 & 83.5 & 1.973 & 1.446 & 1158 & 1675 \\
\hline Total & 2063 & 1050 & 504 & 438 & 255 & 27.035 & 27.600 & 3658 & 4501 \\
\hline Mean & - & - & - & - & - & 1.126 & 1.150 & - & - \\
\hline
\end{tabular}

time, and the two groups are $G_{a}$ (Laterals 101 to 122 ) and $G_{\mathrm{b}}$ (Laterals 123 to 144 ). As mentioned earlier, the coefficient of efficiency (CE) is used to compare the model performance. When $\mathrm{CE}$ is equal to 1 , the amount of water actually distributed matches the projected water demand. For Cases $S_{1}, S_{2}$ and $S_{3}$ (minor water deficient conditions), the corresponding CE's are 1.0, 0.999 and 0.998 , respectively. It should be noted that the modified and the original $K$-factor methods yield the same results for Cases $S_{1}, S_{2}$ and $S_{3}$. For Case $S_{4}$, a comparison of the CE's shows that the modified $K$-factor method proposed in this paper is better than the original $K$-factor method. The advantage of the modified $K$-factor method over the original $K$-factor method can also be shown from $K$ factor values. When $K_{k}$ or $\widetilde{K}_{k}$ is less than 1 , the water actually delivered to lateral intakes cannot meet the project demand. For Case $S_{4}$, the modified $K$-factor method results in $K$-factors of $1.00,1.03$ and 1.04 , while the original $K$-factor method yields $K$-factors of $0.92,1.01$ and 0.99 . Based on these two criteria,
$\mathrm{CE}$ and $K$-factor, one can conclude that the modified $K$-factor method is to be preferred. Hence, only the modified $K$-factor method is applied to the severest water shortage case $\left(\right.$ Case $\left.S_{5}\right)$. The resulting values of $\widetilde{K}_{k}$ are 1.10 and 1.08 , and the value of CE is 0.983 . It is shown that the proposed modified $K$-factor has very good performance even for the severest case.

Figure 4 presents the schematic diagram of the irrigation system of Case $S_{4}$. In Case $S_{4}$, two out of three groups (i.e., $G_{1}+G_{2}, G_{2}+G_{3}, G_{3}+G_{1}$ ) are irrigated at a time. Using the $G_{1}+G_{2}$ in Case $S_{4}$ as an example (see Table 3), the water available at the main intake is $43,698 \mathrm{~L} / \mathrm{s}$. The modified $K$-factor method can deliver $41,017 \mathrm{~L} / \mathrm{s}$ to the lateral intakes. However, the $K$-factor method can only deliver $37,802 \mathrm{~L} / \mathrm{s}$ to the lateral intakes. The difference is $3,215 \mathrm{~L} / \mathrm{s}$. This amount of water is not received by the lateral intakes. Water remains in the main canal and flows further downstream. Such a waste of water is due to the fact that the $K$-factor did not exclude the conveyance loss of the non-irrigated group. 
Table 2 Water demand at farm, lateral and main intakes for each lateral

\begin{tabular}{|c|c|c|c|c|c|c|c|c|c|c|c|}
\hline \multirow[t]{2}{*}{$\begin{array}{l}\text { Lateral } \\
\text { number }\end{array}$} & \multicolumn{5}{|c|}{$\begin{array}{l}\text { Area } \\
\text { (ha) }\end{array}$} & \multicolumn{3}{|c|}{$\begin{array}{c}\text { Conveyance loss } \\
\text { coefficient }\end{array}$} & \multicolumn{3}{|c|}{$\begin{array}{c}\text { Water demand } \\
(\mathrm{L} / \mathrm{s})\end{array}$} \\
\hline & Rice & $\begin{array}{l}\text { Sugar } \\
\text { cane }\end{array}$ & Corn & Peanuts & $\begin{array}{l}\text { Vege-t } \\
\text { tables }\end{array}$ & $\overline{\text { Farm }}$ & Lateral & Main & $\begin{array}{l}\text { Farm } \\
\text { intake }\end{array}$ & $\begin{array}{c}\text { Lateral } \\
\text { intake }\end{array}$ & $\begin{array}{c}\text { Main } \\
\text { intake }\end{array}$ \\
\hline 101 & 274 & 0 & 0 & 0 & 0 & 1.062 & 1.035 & 1.017 & 314 & 325 & 330 \\
\hline 102 & 2915 & 884 & 243 & 243 & 88 & 1.285 & 1.210 & 1.017 & 4110 & 4973 & 5060 \\
\hline 103 & 408 & 102 & 34 & 34 & 34 & 1.082 & 1.058 & 1.039 & 485 & 513 & 533 \\
\hline 104 & 241 & 60 & 20 & 20 & 20 & 1.051 & 1.052 & 1.044 & 278 & 292 & 305 \\
\hline 105 & 395 & 99 & 33 & 33 & 33 & 1.072 & 1.055 & 1.042 & 465 & 490 & 511 \\
\hline 106 & 2063 & 1050 & 504 & 438 & 255 & 1.126 & 1.150 & 1.050 & 3658 & 4501 & 4725 \\
\hline 107 & 2099 & 554 & 245 & 175 & 75 & 1.124 & 1.145 & 1.050 & 2597 & 2973 & 3121 \\
\hline 108 & 195 & 0 & 0 & 0 & 0 & 1.046 & 1.021 & 1.003 & 220 & 225 & 225 \\
\hline 109 & 737 & 0 & 0 & 0 & 0 & 1.052 & 1.085 & 1.003 & 836 & 907 & 910 \\
\hline 110 & 423 & 0 & 0 & 0 & 0 & 1.048 & 1.036 & 1.008 & 478 & 495 & 499 \\
\hline 111 & 2037 & 534 & 230 & 170 & 85 & 1.123 & 1.142 & 1.018 & 2517 & 2875 & 2927 \\
\hline 112 & 139 & 0 & 0 & 0 & 0 & 1.020 & 1.022 & 1.027 & 153 & 156 & 160 \\
\hline 113 & 240 & 0 & 0 & 0 & 0 & 1.045 & 1.032 & 1.034 & 270 & 279 & 289 \\
\hline 114 & 384 & 0 & 0 & 0 & 0 & 1.087 & 1.035 & 1.039 & 450 & 466 & 484 \\
\hline 115 & 1116 & 279 & 93 & 93 & 93 & 1.118 & 1.112 & 1.042 & 1371 & 1524 & 1589 \\
\hline 116 & 462 & 116 & 39 & 39 & 39 & 1.089 & 1.068 & 1.047 & 553 & 590 & 618 \\
\hline 117 & 320 & 80 & 27 & 27 & 27 & 1.068 & 1.051 & 1.055 & 375 & 395 & 416 \\
\hline 118 & 922 & 231 & 77 & 77 & 77 & 1.121 & 1.103 & 1.055 & 1135 & 1252 & 1322 \\
\hline 119 & 471 & 118 & 39 & 39 & 39 & 1.085 & 1.085 & 1.085 & 562 & 610 & 661 \\
\hline 120 & 472 & 118 & 39 & 39 & 39 & 1.092 & 1.085 & 1.085 & 566 & 614 & 666 \\
\hline 121 & 2895 & 880 & 241 & 241 & 85 & 1.281 & 1.221 & 1.085 & 4070 & 4969 & 5390 \\
\hline 122 & 597 & 197 & 50 & 50 & 2 & 1.101 & 1.092 & 1.094 & 721 & 787 & 861 \\
\hline 123 & 1023 & 341 & 85 & 85 & 0 & 1.120 & 1.121 & 1.094 & 1257 & 1409 & 1542 \\
\hline 124 & 449 & 112 & 37 & 37 & 37 & 1.087 & 1.065 & 1.099 & 537 & 571 & 628 \\
\hline 125 & 1088 & 318 & 91 & 91 & 45 & 1.122 & 1.128 & 1.104 & 1340 & 1511 & 1669 \\
\hline 126 & 811 & 203 & 68 & 68 & 68 & 1.116 & 1.109 & 1.105 & 995 & 1103 & 1218 \\
\hline 127 & 355 & 89 & 30 & 30 & 30 & 1.072 & 1.061 & 1.109 & 418 & 444 & 492 \\
\hline 128 & 93 & 23 & 8 & 8 & 8 & 1.032 & 1.020 & 1.116 & 106 & 108 & 120 \\
\hline 129 & 221 & 55 & 18 & 18 & 18 & 1.048 & 1.032 & 1.120 & 254 & 262 & 294 \\
\hline 130 & 269 & 67 & 22 & 22 & 22 & 1.052 & 1.035 & 1.125 & 311 & 322 & 362 \\
\hline 131 & 388 & 777 & 199 & 119 & 99 & 1.118 & 1.115 & 1.125 & 509 & 567 & 638 \\
\hline 132 & 2833 & 959 & 236 & 136 & 86 & 1.218 & 1.182 & 1.140 & 3772 & 4459 & 5084 \\
\hline 133 & 2344 & 1362 & 320 & 120 & 120 & 1.258 & 1.210 & 1.144 & 3242 & 3923 & 4489 \\
\hline 134 & 507 & 1385 & 376 & 317 & 176 & 1.121 & 1.143 & 1.146 & 702 & 803 & 920 \\
\hline 135 & 573 & 744 & 214 & 214 & 114 & 1.120 & 1.138 & 1.178 & 748 & 852 & 1004 \\
\hline 136 & 1017 & 339 & 85 & 85 & 0 & 1.118 & 1.135 & 1.178 & 1247 & 1415 & 1667 \\
\hline 137 & 2345 & 715 & 205 & 205 & 105 & 1.125 & 1.147 & 1.188 & 2898 & 3324 & 3950 \\
\hline 138 & 729 & 182 & 61 & 61 & 61 & 1.116 & 1.102 & 1.188 & 893 & 984 & 1170 \\
\hline 139 & 1015 & 254 & 85 & 85 & 85 & 1.114 & 1.118 & 1.199 & 1243 & 1389 & 1666 \\
\hline 140 & 425 & 142 & 35 & 35 & 0 & 1.068 & 1.063 & 1.212 & 498 & 530 & 642 \\
\hline 141 & 469 & 156 & 39 & 39 & 0 & 1.075 & 1.072 & 1.212 & 553 & 593 & 719 \\
\hline 142 & 408 & 469 & 117 & 117 & 0 & 1.110 & 1.115 & 1.212 & 517 & 577 & 699 \\
\hline 143 & 1617 & 404 & 135 & 135 & 135 & 1.121 & 1.135 & 1.230 & 1991 & 2260 & 2780 \\
\hline 144 & 461 & 715 & 205 & 205 & 105 & 1.117 & 1.125 & 1.233 & 608 & 684 & 844 \\
\hline Total & 39245 & 15112 & 4585 & 3949 & 2303 & 48.626 & 48.266 & 48.400 & 50824 & 58303 & 64199 \\
\hline Mean & - & - & - & - & - & 1.105 & 1.097 & 1.100 & - & - & - \\
\hline
\end{tabular}


Table 3 Water distribution for each lateral under various water shortages using the original and the modified $K$-factor methods

\begin{tabular}{|c|c|c|c|c|c|c|c|c|c|c|c|c|}
\hline \multirow{3}{*}{$\begin{array}{l}\text { Lateral } \\
\text { number }\end{array}$} & \multirow{3}{*}{$\begin{array}{c}\text { Water } \\
\text { demand } \\
\text { at the } \\
\text { lateral } \\
\text { intake } \\
(\mathrm{L} / \mathrm{s})\end{array}$} & \multicolumn{11}{|c|}{ Amount of water delivered to the lateral intake $(\mathrm{L} / \mathrm{s})$} \\
\hline & & \multirow[t]{2}{*}{$S_{1}$} & \multirow[t]{2}{*}{$S_{2}$} & \multirow[t]{2}{*}{$S_{3}$} & \multicolumn{3}{|c|}{$\begin{array}{c}\text { Modified } K \text {-factor } \\
\text { method }\end{array}$} & \multicolumn{3}{|c|}{$K$-factor method } & \multicolumn{2}{|c|}{$\begin{array}{r}S_{5} \\
\text { Modified } \\
K \text {-factor } \\
\text { method }\end{array}$} \\
\hline & & & & & $G_{1}+G_{2}$ & $G_{2}+G_{3}$ & $G_{3}+G_{1}$ & $G_{1}+G_{2}$ & $G_{2}+G_{3}$ & $G_{3}+G_{1}$ & $G_{a}$ & $G_{b}$ \\
\hline 101 & 325 & 320 & 317 & 314 & 325 & 0 & 337 & 299 & 0 & 320 & 358 & 0 \\
\hline 102 & 4973 & 4905 & 4854 & 4811 & 4979 & 0 & 5166 & 4589 & 0 & 4905 & 5483 & 0 \\
\hline 103 & 513 & 506 & 501 & 496 & 514 & 0 & 533 & 473 & 0 & 506 & 566 & 0 \\
\hline 104 & 292 & 288 & 285 & 283 & 293 & 0 & 304 & 270 & 0 & 288 & 322 & 0 \\
\hline 105 & 490 & 484 & 479 & 474 & 491 & 0 & 509 & 452 & 0 & 484 & 541 & 0 \\
\hline 106 & 4501 & 4439 & 4393 & 4354 & 4506 & 0 & 4675 & 4153 & 0 & 4439 & 4962 & 0 \\
\hline 107 & 2973 & 2933 & 2902 & 2877 & 2977 & 0 & 3088 & 2744 & 0 & 2933 & 3278 & 0 \\
\hline 108 & 225 & 221 & 219 & 217 & 225 & 0 & 233 & 207 & 0 & 221 & 248 & 0 \\
\hline 109 & 907 & 895 & 885 & 878 & 908 & 0 & 942 & 837 & 0 & 895 & 1000 & 0 \\
\hline 110 & 495 & 488 & 483 & 479 & 496 & 0 & 514 & 457 & 0 & 488 & 546 & 0 \\
\hline 111 & 2875 & 2835 & 2806 & 2781 & 2878 & 0 & 2986 & 2653 & 0 & 2835 & 3169 & 0 \\
\hline 112 & 156 & 154 & 152 & 151 & 156 & 0 & 162 & 144 & 0 & 154 & 172 & 0 \\
\hline 113 & 279 & 275 & 272 & 270 & 279 & 0 & 290 & 258 & 0 & 275 & 308 & 0 \\
\hline 114 & 466 & 460 & 455 & 451 & 466 & 0 & 484 & 430 & 0 & 460 & 514 & 0 \\
\hline 115 & 1524 & 1503 & 1488 & 1474 & 1526 & 0 & 1583 & 1406 & 0 & 1503 & 1680 & 0 \\
\hline 116 & 590 & 582 & 576 & 571 & 591 & 609 & 0 & 545 & 598 & 0 & 651 & 0 \\
\hline 117 & 395 & 389 & 385 & 382 & 395 & 407 & 0 & 364 & 400 & 0 & 435 & 0 \\
\hline 118 & 1252 & 1235 & 1222 & 1212 & 1254 & 1292 & 0 & 1156 & 1269 & 0 & 1381 & 0 \\
\hline 119 & 610 & 601 & 595 & 590 & 610 & 629 & 0 & 562 & 618 & 0 & 672 & 0 \\
\hline 120 & 614 & 606 & 600 & 594 & 615 & 634 & 0 & 567 & 622 & 0 & 677 & 0 \\
\hline 121 & 4969 & 4901 & 4850 & 4807 & 4975 & 5124 & 0 & 4585 & 5035 & 0 & 5478 & 0 \\
\hline 122 & 787 & 776 & 768 & 761 & 788 & 811 & 0 & 726 & 797 & 0 & 867 & 0 \\
\hline 123 & 1409 & 1390 & 1375 & 1363 & 1411 & 1453 & 0 & 1300 & 1428 & 0 & 0 & 1520 \\
\hline 124 & 571 & 564 & 558 & 553 & 572 & 589 & 0 & 527 & 579 & 0 & 0 & 616 \\
\hline 125 & 1511 & 1491 & 1475 & 1462 & 1513 & 1559 & 0 & 1395 & 1531 & 0 & 0 & 1630 \\
\hline 126 & 1103 & 1088 & 1077 & 1067 & 1104 & 1138 & 0 & 1018 & 1118 & 0 & 0 & 1190 \\
\hline 127 & 444 & 438 & 433 & 430 & 444 & 458 & 0 & 410 & 450 & 0 & 0 & 479 \\
\hline 128 & 108 & 106 & 105 & 104 & 108 & 111 & 0 & 100 & 109 & 0 & 0 & 116 \\
\hline 129 & 262 & 259 & 256 & 254 & 262 & 270 & 0 & 242 & 266 & 0 & 0 & 283 \\
\hline 130 & 322 & 318 & 314 & 312 & 323 & 332 & 0 & 297 & 326 & 0 & 0 & 348 \\
\hline 131 & 567 & 559 & 554 & 549 & 568 & 585 & 0 & 523 & 575 & 0 & 0 & 612 \\
\hline 132 & 4459 & 4398 & 4352 & 4314 & 4464 & 4599 & 0 & 4114 & 4518 & 0 & 0 & 4810 \\
\hline 133 & 3923 & 3869 & 3828 & 3795 & 0 & 4045 & 4074 & 0 & 3974 & 3869 & 0 & 4231 \\
\hline 134 & 803 & 791 & 783 & 776 & 0 & 828 & 834 & 0 & 813 & 791 & 0 & 866 \\
\hline 135 & 852 & 840 & 831 & 824 & 0 & 878 & 885 & 0 & 863 & 840 & 0 & 919 \\
\hline 136 & 1415 & 1395 & 1381 & 1369 & 0 & 1459 & 1470 & 0 & 1434 & 1395 & 0 & 1526 \\
\hline 137 & 3324 & 3279 & 3244 & 3216 & 0 & 3428 & 3453 & 0 & 3368 & 3279 & 0 & 3586 \\
\hline 138 & 984 & 971 & 961 & 952 & 0 & 1015 & 1023 & 0 & 997 & 971 & 0 & 1062 \\
\hline 139 & 1389 & 1370 & 1356 & 1344 & 0 & 1433 & 1443 & 0 & 1408 & 1370 & 0 & 1499 \\
\hline 140 & 530 & 522 & 517 & 512 & 0 & 546 & 550 & 0 & 537 & 522 & 0 & 571 \\
\hline 141 & 593 & 585 & 579 & 574 & 0 & 612 & 616 & 0 & 601 & 585 & 0 & 640 \\
\hline 142 & 577 & 569 & 563 & 558 & 0 & 595 & 599 & 0 & 584 & 569 & 0 & 622 \\
\hline 143 & 2260 & 2229 & 2205 & 2186 & 0 & 2330 & 2347 & 0 & 2290 & 2229 & 0 & 2438 \\
\hline 144 & 684 & 675 & 668 & 662 & 0 & 706 & 711 & 0 & 693 & 675 & 0 & 738 \\
\hline Total & 58303 & 57502 & 56902 & 56402 & 41017 & 38474 & 39810 & 37802 & 37802 & 37802 & 33308 & 30303 \\
\hline
\end{tabular}


Table 3 Water distribution for each lateral under various water shortages using the original and the modified $K$-factor methods (Continue)

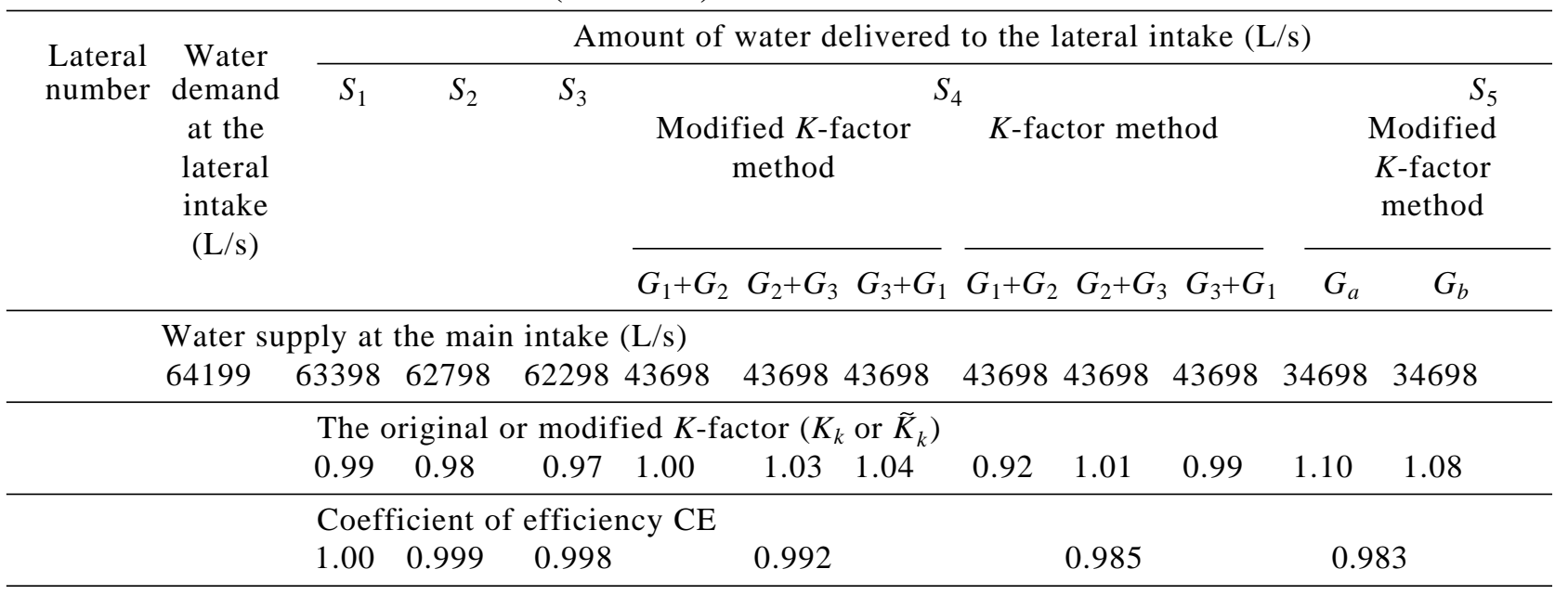

Note:

$S_{1}, S_{2}, S_{3}, S_{4}$, and $S_{5}$ refer to water shortages of $801,1401,1901,20501$, and $29501 \mathrm{~L} / \mathrm{s}$, respectively.

$G_{1}, G_{2}$, and $G_{3}$ refer to Laterals 101 to 115,116 to 132 , and 133 to 144 , respectively.

$G_{a}$ and $G_{b}$ refer to Laterals 101 to 122 and 123 to 144 , respectively.

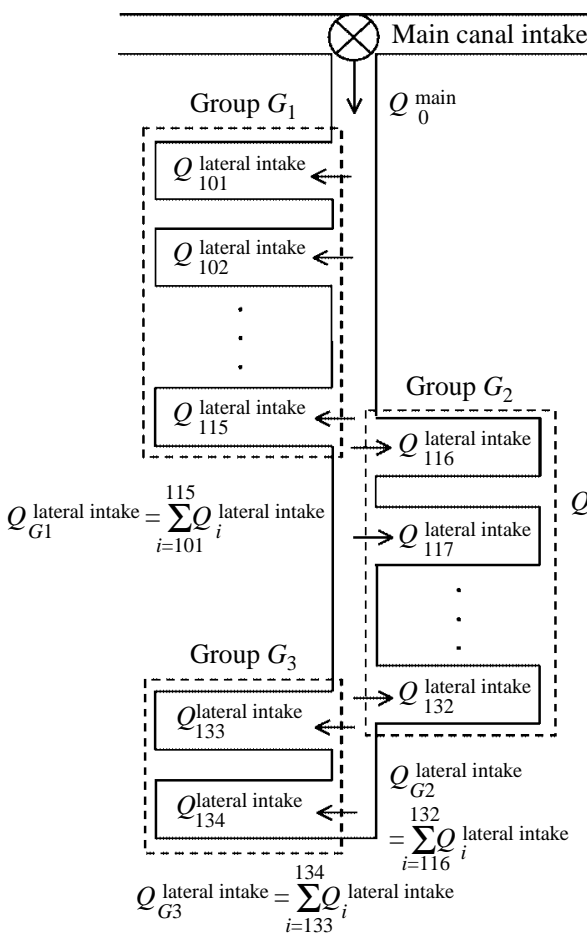

(a)

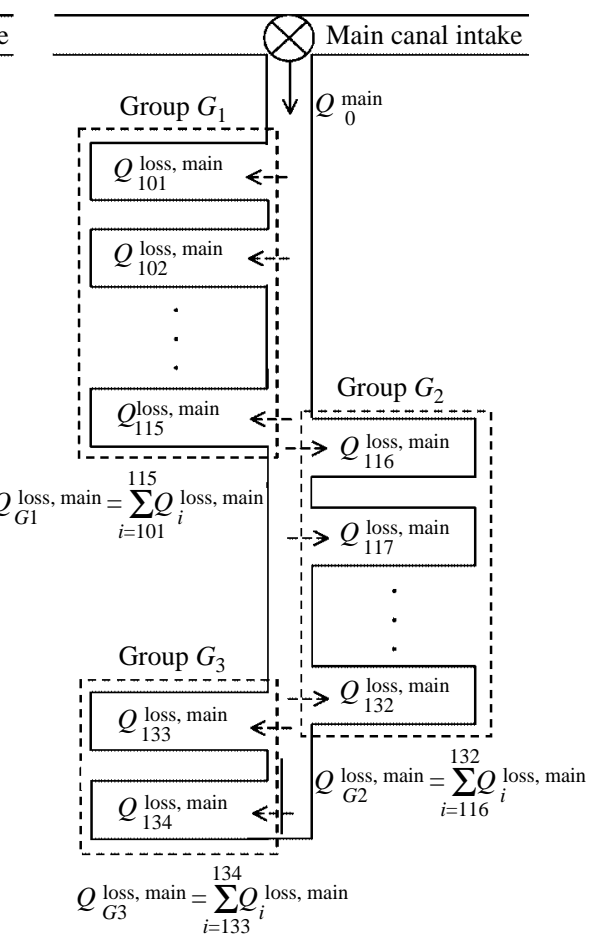

(b)

Fig. 4 A three-group irrigation system illustrating the water distribution in the main canal: (a) water delivered to lateral intakes, and (b) water lost between the main and lateral intakes

\section{(ii) Water Distribution in Lateral Canals}

In a like manner, water distribution schemes can be applied to a lateral system. Lateral 106 is presented herein as an example. Three water deficits, namely 801, 1401 and 1901 (referred to as $S_{1}, S_{2}$ and $S_{3}$ in Table 4), are considered. Table 4 presents the amounts of water delivered to each farm unit under various water shortages using the original and the modified $K$-factor methods. According to the 
Table 4 Water distribution for each farm unit of Lateral 106 under various water shortages using the original and the modified $K$-factor methods

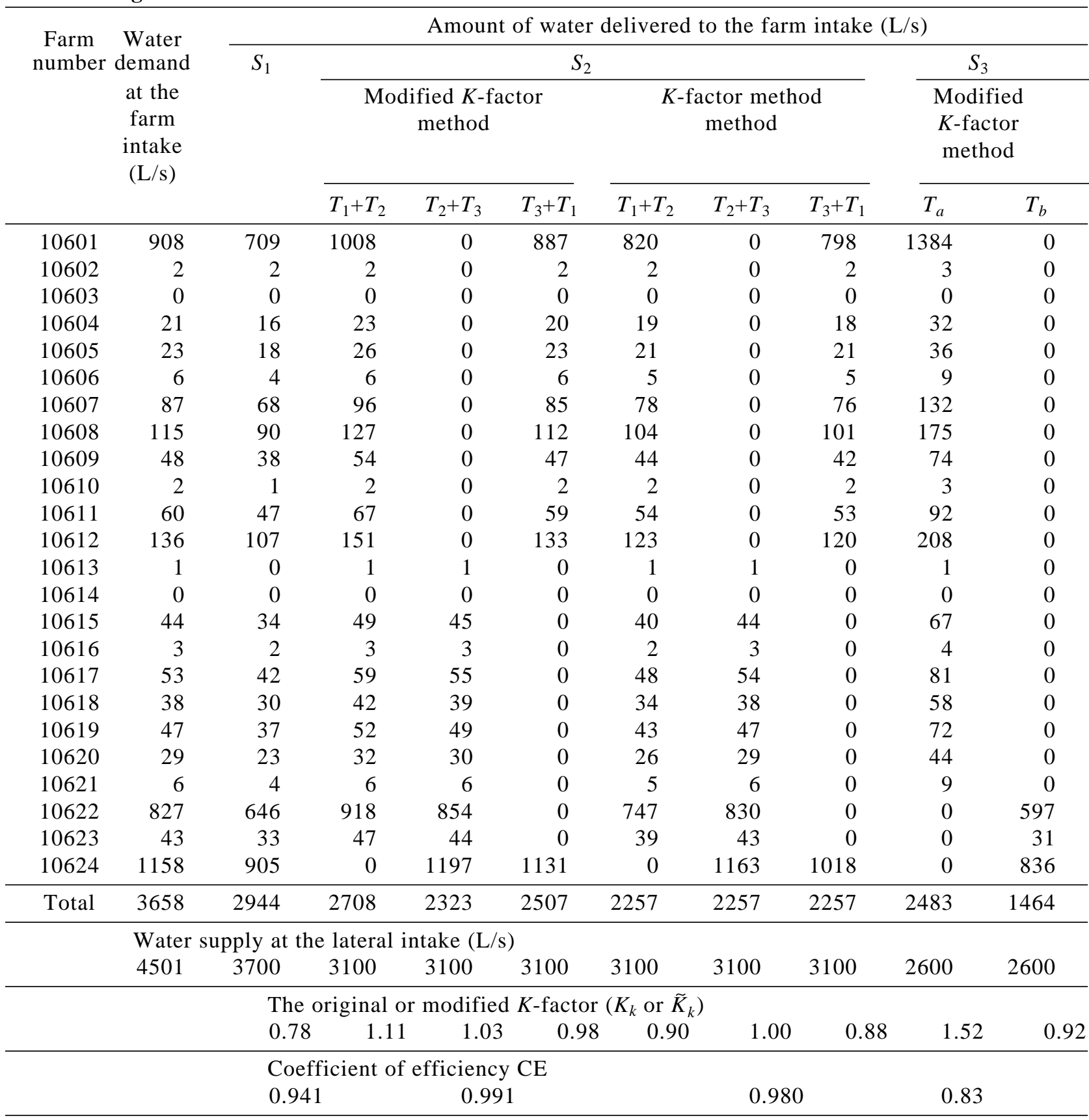

Note:

$S_{1}, S_{2}$, and $S_{3}$ refer to water shortages of 801,1401 , and $1901 \mathrm{~L} / \mathrm{s}$, respectively.

$T_{1}, T_{2}$, and $T_{3}$ refer to farm units 10601 to 10612,10613 to 10623 , and 10624 , respectively.

$T_{a}$ and $T_{b}$ refer to farm units 10601 to 10621 and10622 to 10624 , respectively.

methodology presented in Section III.2, the uniform reduction method is adopted for Case $S_{1}\left(K_{k}=0.78\right)$, and the rotation among irrigation groups method are employed for Cases $S_{2}\left(K_{k}=0.62\right)$ and $S_{3}\left(K_{k}=0.48\right)$. For Case $S_{2}$, two out of three groups are irrigated at a time, and the three groups are $T_{1}$ (Farm units 10601 to 10612 ), $T_{2}$, (Farm units 10613 to 10623 ), and $T_{3}$
(Farm unit 10624). As to Case $S_{3}$, one out of two groups is irrigated at a time, and the two groups are $T_{\mathrm{a}}$ (Farm units 10601 to 10621 ) and $T_{\mathrm{b}}$ (Farm units 10622 to 10624 ). For Case $S_{2}$, the modified $K$-factor method results in $K$-factors of $1.11,1.03$ and 0.98 and a CE of 0.991 , while the original $K$-factor method yields $K$-factors of $0.90,1.00$ and 0.88 and a CE of 
0.98. Table 4 also shows that the modified $K$-factor method is to be preferred. However, as shown in Case $S_{3}$, the resulting values of $\widetilde{K}_{k}$ are 1.52 and 0.92 for the first and second rotation groups, respectively. This results from the fact that areas of farm units are not uniform and each farm unit cannot be further divided.

\section{(iii) Comparison of Water Distribution in Main and Lateral Canals}

For Case $S_{1}$, the uniform reduction method is implemented for both the main and lateral canal systems. However, the main canal system has a CE of 1.0 and the lateral system has a CE of 0.941. For Case $S_{2}$, the uniform reduction method is implemented for the main canal system, while the (two out of three groups) rotation among irrigation groups method has to be used for the lateral canal system. For Case $S_{3}$, one can still apply the uniform reduction method to the main canal system, while one has to employ the (one out of two groups) rotation among irrigation groups method for the lateral canal system. When the shortage reaches up to $20,501 \mathrm{~L} / \mathrm{sec}$ (Case $S_{4}$ ), the lateral canal system is incapable of handling the water distribution practice. However, the (two out of three groups) rotation among irrigation groups method can still be applied to the main canal system.

For minor water deficits, the water distribution in the lateral canal system can be applied using considerations of management and operation cost. However, for severe water shortages, the ratio of water shortage to the lateral's projected water demand is high. Hence, water distribution from the main canal system has to be employed.

\section{CONCLUSIONS}

In this paper, a water distribution model is proposed which is capable of satisfying water demand in large-scale mixed cultivation irrigation areas during water shortage periods. The proposed model is based on a new parameter called the modified $K$ factor. Actual applications of the model are performed. It is found that the proposed model is better than the model based on the original $K$-factor. The model can be applied to either a main or to a lateral canal system. According to the simulated results, it is suggested to employ water distribution in the lateral canal system for minor water-shortage conditions. However, for severe water shortages, the practice of water distribution from the main canal system is recommended. The proposed model can deliver appropriate amounts of irrigation water to specific blocks at the right time, fairly and rationally, under various circumstances, while agricultural production is not affected.

\section{NOMENCLATURE}

$A_{\text {exp }}$

$A_{i}$

$A_{i j}$

C

$C_{\exp }$

$\mathrm{CC}_{j k}$

$\mathrm{CE}_{k}$

CLC

CLC $^{\text {farm }}$

$\mathrm{CLC}_{i}^{\text {lateral }}$

$\mathrm{CLC}_{i}^{\text {main }}$

$\mathrm{ET}_{k}^{\mathrm{refer}}$

$i$

j

$k$

$K_{k}$

$\widetilde{K}_{k}$

$L_{i}$

$n$

$q_{j}^{\mathrm{p}}$

$q_{j k}^{\mathrm{CWR}}$

$q_{j k}^{\mathrm{ER}}$

$q_{j k}^{\mathrm{FIR}}$

$Q_{i k}$

$Q_{i k}^{\text {actual }}$

$\bar{Q}_{k}$

$Q_{k}^{\text {actual }}$

$Q_{k}^{\text {loss }}$ area of an experimental farm

area of the $i$ th farm unit

area for the $j$ th crop in the $i$ th farm unit water loss in canals (in decimals)

experimental water loss in canals (in decimals)

crop coefficient for the $j$ th crop during the $k$ th irrigation period

coefficient of efficiency during the $k$ th irrigation period

conveyance loss coefficient

conveyance loss coefficient for farm units

conveyance loss coefficient for the lateral canal which delivers water to the $i$ th farm intake

conveyance loss coefficient for main canal between the main intake and the lateral intake from which water is delivered to the $i$ th farm intake

reference evapotranspiration of standard crop canopy during the $k$ th irrigation period per hectare of irrigation area index corresponding to the farm unit index corresponding to the crop type index corresponding to the irrigation period

$K$-factor for the $k$ th irrigation period modified $K$-factor for the $k$ th irrigation period

canal length from the canal intake to the $i$ th farm unit

number of farm units

percolation in paddy fields for the $j$ th crop per hectare of irrigation area crop water requirement for the $j$ th crop during the $k$ th irrigation period per hectare of irrigation area

effective rainfall for the $j$ th crop during the $k$ th irrigation period per hectare of irrigation area

field irrigation requirement for the $j$ th crop during the $k$ th irrigation period per hectare of irrigation area

projected farm water demand for the $k$ th irrigation period in the $i$ th farm unit actual amount of water delivered to the $i$ th farm unit during the $k$ th irrigation period average farm water demand during the $k$ th irrigation period

actual amount of water delivered to the system during the $k$ th irrigation period conveyance loss of the system during the $k$ th irrigation period 


\begin{tabular}{|c|c|}
\hline$Q_{k}^{\text {project }}$ & $\begin{array}{l}\text { projected water demand of the system } \\
\text { during the } k \text { th irrigation period }\end{array}$ \\
\hline$Q_{i j k}^{\text {project, farm }}$ & $\begin{array}{l}\text { projected water demand at the farm in- } \\
\text { take for the } j \text { th crop in the } i \text { th farm unit } \\
\text { during the } k \text { th irrigation period }\end{array}$ \\
\hline$Q_{i j k}^{\text {project, main }}$ & $\begin{array}{l}\text { projected water demand at the main ca- } \\
\text { nal intake for the } j \text { th crop in the } i \text { th farm } \\
\text { unit during the } k \text { th irrigation period }\end{array}$ \\
\hline$\widetilde{Q}_{i k}^{\text {project, farm }}$ & $\begin{array}{l}\text { modified projected farm water demand } \\
\text { for the } i \text { th farm unit during the } k \text { th Irri- } \\
\text { gation period }\end{array}$ \\
\hline$Q_{k}^{\text {loss, lateral }}$ & $\begin{array}{l}\text { water loss of a lateral canal during the } \\
k \text { th irrigation period }\end{array}$ \\
\hline$Q_{k}^{\text {loss, main }}$ & $\begin{array}{l}\text { water loss of a main canal during the } k \text { th } \\
\text { irrigation period }\end{array}$ \\
\hline$Q_{k}^{\text {project, lateral }}$ & $\begin{array}{l}\text { projected water demand at a lateral canal } \\
\text { intake during the } k \text { th irrigation period }\end{array}$ \\
\hline$Q_{k}^{\text {project, main }}$ & $\begin{array}{l}\text { projected water demand at a main canal } \\
\text { intake during the } k \text { th irrigation period }\end{array}$ \\
\hline$r$ & number of crop types \\
\hline$S$ & water loss in ditches of a farm (in decimals) \\
\hline$S_{\exp }$ & $\begin{array}{l}\text { the experimental water loss of a farm } \\
\text { with an area of } A_{\exp } \text { (in decimals) }\end{array}$ \\
\hline
\end{tabular}

\section{REFERENCES}

Chang, Y. C., Kan, C. E., Lin, G. F., Lee, Y. C., and Chiu, C. L., 2001, "Potential Benefits of Increased Application of Water to Paddy Fields in Taiwan," Hydrological Processes, Vol. 15, No. 8, pp. 1515-1524.

Chen, C. T., Chen, K. Y., Kan, C. E., and Shih, S. F., 1997, "Mobile Irrigation Water Management in Paddy Field," Journal of Taiwan Water Conservancy, Vol. 45, No. 3, pp. 8-29. (in Chinese)

Chen, C. T., Chen, K. Y., Kan, C. E., and Shih, S. F., 1998, "Modified Rotational Irrigation in Water Short Environments," Proceedings of the 49th International Executive Council Meetings and the 10th Afro-Asian Regional Conference of the International Commission on Irrigation and Drainage, Bali, Indonesia, Vol. B, Paper No. 21, pp. 1-16.

Cheng, C. T., 1980, "Further Study on Irrigation Operation and Water Distribution Planning for Rice Irrigation System," Journal of Taiwan Water Conservancy, Vol. 28, No. 2, pp. 33-60. (in Chinese)

Doorenbos, J., and Pruitt, W. O., 1977, "Guidelines for Predicting Crop Water Requirements," FAO Irrigation and Drainage Paper 24, Food and Agricultural Organization, Rome, Italy.

Droogers, P., Kite, G., and Bastiaanssen, W., 1999, "Integrated Basin Modeling to Evaluate Water Productivity," Transactions of the 17th Congress of the International Commission on Irrigation and Drainage, Granada, Spain, Vol. 1A, pp. 1-20.
Kan, C. E., 1978, "Irrigation Principles and Practices," Design of Irrigation and Drainage Engineering, Taiwan Water Conservancy Bureau, pp. 18-50. (in Chinese)

Kan, C. E., Chen, C. T., and Chen, K. Y., 1996, "Study on the Suitability of Consumptive Use Estimation Methods for Taiwan Area," Journal of Chinese Agricultural Engineering, Vol. 42, No. 2, pp. 8-19. (in Chinese)

Kan, C. E., Chen, K. Y., and Shih, S. F., 1997a, “A Procedure for Rotational Irrigation in Lowland Rice," Agricultural Water Management, Vol. 35, No. 1-2, pp. 109-121.

Kan, C. E., Chen, K. Y., and Shih, S. F., 1997b, "Irrigation Water Distribution Scheme for Rice Production in Taiwan," Transactions of the ASAE and Applied Engineering in Agriculture, Vol. 13, No. 5, pp. 601-608.

Kan, C. E., and Hsu, C. M., 1984, "Study on Drought Tolerance of Paddy Rice and Water Conservation for Irrigation," Journal of Taiwan Water Conservancy, Vol. 32, No. 1, pp. 4-37. (in Chinese)

Lin, G. H., 1992, "Study on Water Distribution under the Condition of the Uncertain Flow in the Fixed Canal Capacity," Master Thesis, Department of Agricultural Engineering, National Taiwan University, Taipei, Taiwan, pp. 50-70. (in Chinese)

Masakazu, M., 1999, "Development of Paddy Field Engineering in Japan," Advanced Paddy Field Engineering, Japanese Society of Irrigation, Drainage and Reclamation Engineering, pp. 1-9.

Masayoshi, S., 1999, "Crop Diversification in the Toyagawa Irrigation Project, Japan," Transactions of the 17th Congress of the International Commission on Irrigation and Drainage, Granada, Spain, Vol. 1G, pp. 69-76.

Monteith, J. L., 1994, "Proposed Calculation Procedures for $\mathrm{ET}_{0}$ Combination Formula," Bulletin of International Commission on Irrigation and Drainage, Vol. 43, No. 2, pp. 39-82.

Pasandaran, E., Hutabarat, B., and Djunaedi, S., 1989, "Irrigation Management to Support Crop Diversification in Indonesia," Research Network on Irrigation Management for Diversified Cropping in Rice-Based System, International Irrigation Management Institute, Indonesia, pp. 51-66.

Pereira, L. S., Van, B. J., and Allen, R. G., 1993, "Crop-Water-Simulation Model in Practice," Proceedings of the 15th Congress of the International Commission on Irrigation and Drainage, Hague, Netherlands, pp. 287-294.

Manuscript Received: May 02, 2003 Revision Received: Oct. 12, 2003 and Accepted: Nov. 21, 2003 